\title{
EFFECT OF RED ONION (ALLIUM CEPA VAR. AGGREGATUM G. DON) ON SERUM URIC ACID LEVEL AND TOTAL ANTIOXIDANT STATUS IN NORMAL AND INDUCED HYPERURICEMIC RATS
}

\author{
ASMAH RAHMAT ${ }^{*}$, CHOO YEN LENG ${ }^{2}$, FAZLEEN IZZANY ABU BAKAR ${ }^{1,3}$, MOHD FADZELLY ABU BAKAR $^{1,3}$ \\ ${ }^{1}$ Department of Technology and Natural Resources, Faculty of Applied Sciences and Technology, Universiti Tun Hussein Onn Malaysia, Hab \\ Pendidikan Tinggi Pagoh, KM 1, Jalan Panchor, 84600 Muar, Johor, Malaysia. ${ }^{2}$ Department of Nutrition and Dietetics, Faculty of Medicine \\ and Health Sciences, Universiti Putra Malaysia, 43400, UPM Serdang, Selangor, Malaysia. ${ }^{3}$ Centre of Research for Sustainable Uses of \\ Natural Resources, Universiti Tun Hussein Onn Malaysia, Batu Pahat, 86400 Parit Raja, Johor, Malaysia.Email: asmahr@uthm.edu.my
}

Received: 03 August 2017, Revised and Accepted: 23 November 2017

\section{ABSTRACT}

Objective: This study aimed to investigate the effect of onion (Allium cepa var. aggregatum G. Don) on serum uric acid level and total antioxidant status of normal and induced hyperuricemic rats.

Methods: A total of 36 male Sprague-Dawley rats were divided equally into six groups, and $250 \mathrm{mg} / \mathrm{kg}$ of potassium oxonate was injected intraperitoneally on day 1,3 , and 7 to induce hyperuricemia in rats. $7 \mathrm{~d}$ consecutively of treatment were given to the rats by oral gavage. Serum uric acid level was measured $2 \mathrm{~h}$ after the induction on day 1, 3, 7, and 14. Blood plasma was obtained at day 14 to measure its total antioxidant status. The rats were sacrificed by taking out their liver and kidney for histopathological evaluation.

Results: The results showed that onion juice lowered the serum uric acid level in dose-dependent manner. The highest dose (10.5 g/kg/day) appeared to possess the inhibitory effect almost similar to allopurinol. There was an increase in total antioxidant status in a hyperuricemic group treated with onion juice compared to control groups but insignificant. By viewing the histological profile, onion showed to have a protective effect toward the liver damage by hyperuricemia. However, this was not happened in kidney.

Conclusion: Onion lowered the serum uric acid level, but its protective effect toward liver and kidney remained ambiguous. Further investigation with the increase of parameters and inclusion of analytical test of bioactive compound in red onion is recommended for the future studies.

Keywords: Red onion, Hyperuricemia, Uric acid, Induced hyperuricemic rats, Antioxidant.

(C) 2018 The Authors. Published by Innovare Academic Sciences Pvt Ltd. This is an open access article under the CC BY license (http://creativecommons. org/licenses/by/4. 0/) DOI: http://dx.doi.org/10.22159/ajpcr.2018.v11i3.21790

\section{INTRODUCTION}

Uric acid is the end product of purine metabolism where in this reaction, purine nucleic acids are metabolized into hypoxanthine which subsequently converted into uric acid, catalyzed by xanthine oxidase (XO). The increase of uric acid production in blood or decrease of renal excretion of uric acid from the body leads to a life-threatening metabolic complication known as hyperuricemia [1]. High purine diet such as anchovies, various types of seafood, internal organs, and meat may contribute to the elevation of uric acid levels in the body which eventually cause a medical disorder known as gout [2]. Currently, Asian population and people of the Pacific Island are having a higher prevalence of gout [3] where the increasing of prevalence of gout in Asia countries is now approaching western levels. The incidence of gout has doubled and continues to increase over the past two decades [4]. In fact, the risk of gout in male is significantly higher than female with the ratio of 9:1. However, the prevalence seems to increase in postmenopausal women [5]. Gout consists of four stages; asymptomatic hyperuricemia, acute gout, intercritical gout, and chronic tophaceous gout [6]. This condition can be treated by lowering the serum uric acid level and depleting the body urate pool [2]. There are few types of drugs commonly used for treating gout such as allopurinol, febuxostat (XO inhibitors), probenecid, sulfinpyrazone, and benzbromarone (uricosuric drugs) [7], but these drugs may give side effects to our body. Hence, the search for novel antigout agent from the plant is greatly needed as an alternative medicine.

Onion (Allium cepa) possesses various phytochemicals such as flavonoid (quercetin) and phenolic which can be used as pharmaceuticals and nutraceuticals [8]. Onion is considered to be associated with the reducing risk of stomach, brain, and liver cancer in humans [9] and also inhibiting platelet-mediated thrombosis which eventually leads to heart attacks and strokes. Typically, darker color of vegetables like red onion possesses higher nutrient content [10]. Many studies also showed that red onion contained higher antioxidant activity as compared to white and yellow onions $[11,12]$. By considering the presence of various phytochemicals in onion, hence, this study aimed to investigate the effect of red onion (A. cepa var. aggregatum G. Don) on serum uric acid level and total antioxidant status in normal and induced hyperuricemic rats.

\section{MATERIALS AND METHODS}

Chemicals and reagents

Allopurinol (MHRA, UK), potassium oxonate, $10 \%$ buffered formaldehyde, paraffin, metmyoglobin, hydrogen peroxide (Sigma Aldrich, USA), and hematoxylin and eosin (Thermo Fisher Scientific, USA).

\section{Preparation of onion juice}

The onion was bought from Grand Union Supermarket, Serdang and identified by the Institute of Biosciences, Universiti Putra Malaysia (UPM/IBS/UB/H125-13). Then, the outer layer and any inedible outer portions of onion were removed and the remaining edible portions were weighed and blended in distilled water with the ratio of $1: 1 \mathrm{w} / \mathrm{v}$. The freshly prepared onion juice was administered to each animal by oral gavage [13].

Experimental animal

A total of 36 male Sprague-Dawley rats with an average weight of 250$300 \mathrm{~g}$ were used in this study with the approval of Institutional Animal 
Care and Use Committee (UPM/IACUC/FYP-2013/FPSK.R067). They were housed in three separate cages at the animal house of Faculty of Medicine and Health Sciences, UPM, and allowed for acclimatization before the experiment for $7 \mathrm{~d}, 12 \mathrm{~h}$ light/dark cycle at $22^{\circ} \mathrm{C}$ and relative humidity of $50-60 \%$. The rats were fed with standard laboratory diet and allowed for water ad libitum.

\section{Induction of hyperuricemia}

The induced hyperuricemia rats were used to study the antihyperuricemic effects of test compounds [14]. $250 \mathrm{mg} / \mathrm{kg}$ of potassium oxonate (uricase inhibitor) was dissolved in $0.9 \%$ saline solution and administered intraperitoneally to each rat on day 1,3 , and 7 of the experiment [13].

Experimental design and treatment of animals

A total of 36 rats were divided into six equal groups; normal control, hyperuricemic control, hyperuricemic treated with $5 \mathrm{mg} / \mathrm{kg} /$ day allopurinol, hyperuricemic treated with $3.5 \mathrm{~g} / \mathrm{kg} /$ day onion juice, hyperuricemic treated with $7.0 \mathrm{~g} / \mathrm{kg} /$ day onion juice, and hyperuricemic treated with $10.5 \mathrm{~g} / \mathrm{kg} /$ day onion juice. The experiment was carried Out for $7 \mathrm{~d}$ consecutively [13]. Water, allopurinol, and onion juice were given to the rats once daily by oral gavage. Potassium oxonate and allopurinol were dispersed in $0.9 \%$ saline solution, respectively, before administered to the animals. The volume of drugs and test compounds administered was based on the body weight of the rats which measured immediately before each dose. The food was withdrawn from the animals $1 \mathrm{~h}$ before administration [15].

\section{Determination of serum uric acid level}

Approximately $500 \mu \mathrm{l}$ of whole blood sample was taken out from each rat after the administration of test compounds by cutting the tail tip $2 \mathrm{~h}$. The blood sample was centrifuged at $3000 \mathrm{rpm}$ for $10 \mathrm{~min}$ to obtain the serum [13], and the serum uric acid level was determined using an automated analyzer.

\section{Determination of total antioxidant status}

Randox selectra E chemical analyzer was used to test the total antioxidant status. About $3 \mathrm{ml}$ of blood sample was drawn by cardiac puncture and placed into lithium heparin tubes. Then, the blood sample was centrifuged at $3000 \mathrm{rpm}$ for $10 \mathrm{~min}$ at $3{ }^{\circ} \mathrm{C}$ using a refrigerated centrifuge and stored at $-80^{\circ} \mathrm{C}$ to obtain the plasma until further analysis. The 2,2'-Azino-di-[3-ethylbenzthiazoline sulfonate] radical cation was formed by incubating it with metmyoglobin and hydrogen peroxide. The blue-green production of 2,2'-Azino-di-[3-ethylbenzthiazoline sulfonate] in proportion to their concentration was formed to show the presence of the antioxidant in the plasma. The bleaching rate was inversely related to the total antioxidant capacity of the sample. The antioxidant was measured using spectrophotometer at $600 \mathrm{~nm}$.

\section{Liver and kidney histology of normal and induced hyperuricemic} rats

Rats were sacrificed by cervical dislocation, and then, midline laparotomy was performed. The liver and kidney of two representative rats from each group were excised. The excised liver and kidney specimens from the rats in all groups were fixed in $10 \%$ buffered formaldehyde for $24 \mathrm{~h}$, and the specimens were embedded in paraffin after $16 \mathrm{~h}$ of alcohol process. $5 \mu \mathrm{m}$ thick sections of the specimens were obtained from the paraffin blocks and stained with hematoxylin and eosin. The slides were then examined under a light microscope [16]. The histological changes were analyzed using the lesion scoring system for chronic hepatitis where five spots were chosen and observed for each rats $[17,18]$.

\section{Statistical analysis}

The results were expressed as mean \pm standard deviation, $n=6$. The statistical comparison of serum uric acid level and total antioxidant status among groups was performed by one-way analysis of variance (ANOVA). Serum uric acid level before and after treatment was tested using paired sample t-test of Statistical Package for the Social Sciences (SPSS) version 21.0. $\mathrm{p}<0.05$ was considered statistically significant.

\section{RESULTS AND DISCUSSION}

Serum uric acid level in normal and hyperuricemic groups before the treatment.

Most of the mammals except man possess the uricase enzyme which important in eliminating uric acid in the body by catalyzing the conversion of uric acid to allantoin (more soluble) [19]. To induce hyperuricemia in an animal model, the uricase must be blocked to inhibit the formation of allantoin. Potassium oxonate, a uricase inhibitor, is employed frequently in various studies to develop hyperuricemic animal model. As expected, the serum uric acid level of the hyperuricemic groups increased significantly as compared to the normal control group after pretreated with $250 \mathrm{mg} / \mathrm{kg}$ potassium oxonate at day 1,3 , and 7 of the study (Fig. 1). This result indicated that the rats were successfully induced to be hyperuricemic by intraperitoneal injection of $250 \mathrm{mg} / \mathrm{kg}$ potassium oxonate. The outcome was in line with a study by Haidari et al. [13] which also successfully induced hyperuricemia in rats using the same method. In contrast, another study also used an intraperitoneal injection of the same dose of potassium oxonate to induce hyperuricemia. However, the induction period in this study was doubled as compared to the previous study [20]. Apart from an intraperitoneal injection, there were few studies used different methods to induce hyperuricemia using potassium oxonate. Schwartz et al. [21] induced hyperuricemic in rats by the method of oral gavage $(750 \mathrm{mg} / \mathrm{kg} /$ day for 4 weeks $)$ and the dosage used was three-fold of the dosage in this study. However, the serum uric acid after 4 weeks of induction was only 1.7 $\pm 0.2 \mathrm{mg} / \mathrm{dl}$ although this value increased significantly as compared to the normal rats. Besides, other study also used oral gavage method with the same amount of potassium oxonate for $4 \mathrm{w}$ consecutively [22]. The serum uric acid increased significantly as compared to its normal group, but still, the value obtained after 4 weeks was lower than the serum uric acid level after induced by intraperitoneal injection in this study with $3.1 \pm 0.5 \mathrm{mg} / \mathrm{dl}$. From this comparison, an intraperitoneally injection might be more effective than oral administration to induce hyperuricemia in a shorter period.

Serum uric acid level in normal and hyperuricemic groups before and after the treatment

After $7 \mathrm{~d}$ of treatment consecutively, serum uric acid level of hyperuricemic group received $5 \mathrm{mg} / \mathrm{kg} /$ day of allopurinol decreased significantly after the treatment. This result was possible as allopurinol

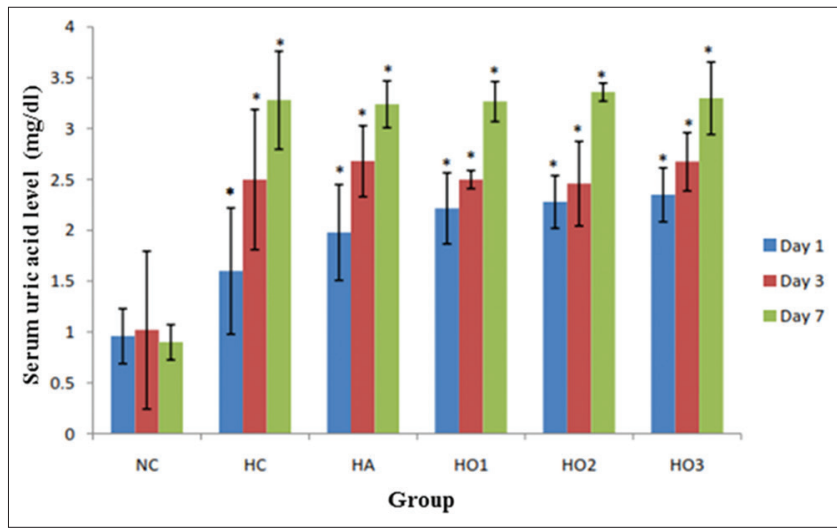

Fig. 1: Serum uric acid level in normal and hyperuricemic groups at day 1, 3, and 7 after induction with $250 \mathrm{mg} / \mathrm{kg}$ potassium oxonate before treatment. Data represented as mean \pm standard deviation, $n=6$. For statistical significance, least significant difference test was used.

*Indicates $\mathbf{p}<0.05$ as compared to the serum uric acid levels of normal groups. NC: Normal Group; HC:

Hyperuricemic control; HA: Hyperuricemic $+5 \mathrm{mg} / \mathrm{kg} / \mathrm{day}$ allopurinol; HO1: Hyperuricemic $+3.5 \mathrm{~g} / \mathrm{kg} / \mathrm{day}$; HO2: Hyperuricemic+7.0g/kg/day; HO3:Hyperuricemic+10.5g/kg/day 
(xanthine inhibitor) was the first-line pharmacologic urate-lowering therapy in the management of gout [23] and frequently used as a positive control in the animal study of hyperuricemia. Previous studies also showed that the serum uric acid level in hyperuricemic rats reduced after receiving $5 \mathrm{mg} / \mathrm{kg} /$ day of allopurinol [15,24,25]. Besides allopurinol, serum uric acid of hyperuricemic group treated with three different doses of onion juice also reduced significantly in dose-dependent manner after the treatment (Fig. 2). This finding was in agreement with Haidari et al., [13] of which $3.5 \mathrm{~g} / \mathrm{kg} / \mathrm{day}$ onion was able to reduce serum uric acid level in rats as well as $7.0 \mathrm{~g} / \mathrm{kg} /$ day of onion juice. In this study, a higher dose of onion juice $(10.5 \mathrm{~g} / \mathrm{kg} / \mathrm{day})$ was given to the hyperuricemic rats, and the serum uric acid level appeared to decrease more than the moderate dose $(7.0 \mathrm{~g} / \mathrm{kg} / \mathrm{day})$. This finding was further confirmed the dose-dependent manner of reduction in serum uric acid level of hyperuricemic group. The results obtained from this study also supported the finding from Haidari et al. [13] where the hypouricemic effects of onion juice might be due to the presence of flavonoids which exerted inhibitory effects on $\mathrm{XO}$ and xanthine dehydrogenase enzyme activities. The main subclasses of flavonoids present in onions are flavonols and anthocyanins while quercetin 3,4'-diglucoside and quercetin 4'-monoglucoside are the main flavonols found in onion [26]. These components are believed to be associated with the reduction of uric acid in the blood. In contrast, Hu et al. [27] suggested that the ability of quercetin to exert uricosuric effect and promoted the renal excretion of uric acid was the main mechanism led to the reduction of serum uric acid level in hyperuricemic rats. Vitamin $\mathrm{C}$ which found highly in onion might be associated to the lowering of serum uric acid. A study also showed that Vitamin C supplementation was able to reduce serum uric acid level [22]. The ability of Vitamin $C$ to exert the uricosuric effect by competition for renal reabsorption of uric acid through an anion exchange transport system and also increase of glomerular filtration rate is the possible mechanisms in lowering the uric acid level [28].

Serum uric acid level in hyperuricemic groups after the treatment After the treatment, the final serum uric acid level was measured. The serum uric acid level of the hyperuricemic groups treated with the highest dose of onion juice was almost similar to the allopurinol treatment. Based on Fig. 3, it showed that $10.5 \mathrm{~g} / \mathrm{kg} /$ day of onion juice might be potentially used as a substitution of allopurinol in the management of gout. Purwantiningsih et al. [29] also reported that the antihyperuricemic activity of the ethanol (60.86-78.33\%) and hexane extracts (78.23-88.52\%) of Kepel leaves were almost similar to that of allopurinol (50.82-91.16\%) at the end of day post-treatment. Higher dose of allopurinol contributes to some health benefits such as improves the endothelial function, cardiac structure, and reduces blood pressure [30,31]. This implies higher dose of allopurinol may reduce the risk of getting cardiovascular disease. However, there are few previous evidences suggest that allopurinol gives side effects to our body. A retrospective study by Lee et al. [32] postulated that there was a case of allopurinol hypersensitivity syndrome. Although approximately $1 \%$ of patients were affected, still, this could be fatal. On top of that, Halevy et al. [33] revealed that allopurinol consumption contributed to a few diseases such as Stevens-Johnson syndrome and toxic epidermal necrolysis. Hence, onions are suggested to be one of the natural substitutions of allopurinol with fewer side effects.

Total antioxidant status of normal and hyperuricemic groups after the treatment

In this study, the total antioxidant status of hyperuricemic control group was lower than the normal control group (Fig. 4). This finding supported a study by Haidari et al. [13] where high serum uric acid level lowered the total antioxidant status of rats. Interestingly, there are few studies suggest that uric acid plays a role of antioxidant in the body. Study by Naghavi et al. [34] postulated that uric acid exhibited its antioxidant properties in the early stages of atherosclerotic process. However, when the serum uric acid in the body increased beyond the reference normal range, the antioxidant state will be reversed into a prooxidant state in later stages of the atherosclerotic process. In addition, uric acid displayed good antioxidant properties as it accounted

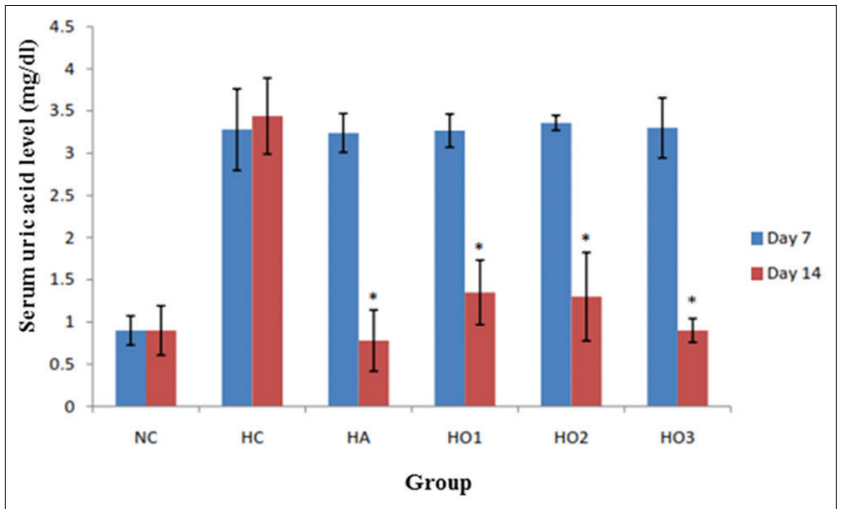

Fig. 2: Serum uric acid level in normal and hyperuricemic groups before and after treatment. Data represented as mean \pm standard deviation, $n=6$. For statistical significance, paired sample t-test was used. *Indicates $p<0.05$ when compared to the serum uric acid levels in all groups before treatment. NC:Normal Group; HC: Hyperuricemic control;

HA: Hyperuricemic $+5 \mathrm{mg} / \mathrm{kg} /$ day allopurinol; HO1: Hyperuricemic+3.5 g/kg/day; HO2: Hyperuricemic+7.0 g/kg/day; HO3: Hyperuricemic $+10.5 \mathrm{~g} / \mathrm{kg} /$ day)

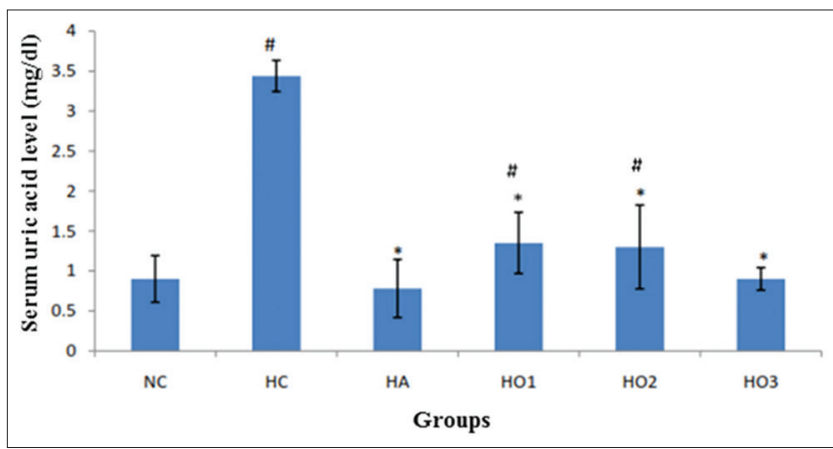

Fig. 3: Serum uric acid level in hyperuricemic groups after treatment. Data represented as mean \pm standard deviation, $n=6$. For statistical significance, least significant difference test was used. $*$ Indicates $\mathbf{p}<\mathbf{0 . 0 5}$ when compared to the serum uric acid levels of hyperuricemic control group; \#indicates $p<0.05$ when compared to the serum uric acid levels of hyperuricemic $+5 \mathrm{mg} / \mathrm{kg} /$ day allopurinol group. NC: Normal Group; HC: Hyperuricemic control; HA: Hyperuricemic+ $5 \mathrm{mg} / \mathrm{kg} /$ day allopurinol; H01: Hyperuricemic+ $3.5 \mathrm{~g} / \mathrm{kg} / \mathrm{day}$; HO2: Hyperuricemic $+7.0 \mathrm{~g} / \mathrm{kg} /$ day; H03: Hyperuricemic $+10.5 \mathrm{~g} / \mathrm{kg} /$ day)

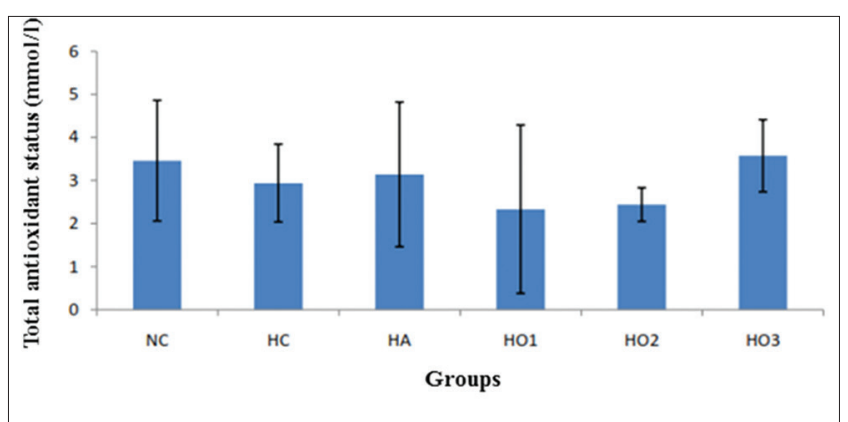

Fig. 4: Total antioxidant status in normal and hyperuricemic groups after treatment. Data represented as mean \pm standard deviation, $n=6$. For statistical significance, least significant difference test was used. There were no any significant differences among groups. NC: Normal Group; HC: Hyperuricemic control; HA: Hyperuricemic $+5 \mathrm{mg} / \mathrm{kg} /$ day allopurinol; HO1: Hyperuricemic+3.5 g/kg/day; HO2: Hyperuricemic+7.0 g/kg/day; H03: Hyperuricemic $+10.5 \mathrm{~g} / \mathrm{kg} /$ day) 
for almost half of the antioxidant capacity of human plasma. In this study, onion increased the total antioxidant status in hyperuricemic rats more than those treated with allopurinol after the treatment. This finding was in line with Haidari et al. [13] where the total antioxidant status of the hyperuricemic rats increased after receiving $5 \mathrm{~g} / \mathrm{kg} /$ day of onion for $2 \mathrm{w}$. Onion is a well-known antioxidant-rich raw vegetable. The intense color vegetables such as red onion and red cabbage were found to contain a higher value of antioxidant activity compared to other vegetables [35]. The same result also was reported by Gorinstein et al. [36] where red onion appeared to contain the highest antioxidant activity in methanol extracts compared to garlic, green peppers, white cabbage, and white and yellow onion. Thus, it is believed that the consumption of red onion increases the total antioxidant status of rats.

Histological changes in normal and hyperuricemic groups after the treatment

The histological changes were observed in the liver and kidney of the hyperuricemic control group as compared to the normal control group after the treatment in this study. The induced hyperuricemic caused damage to the liver and kidney and interrupted their function in the body. According to Liu et al. [37], excessive reaction oxygen species (ROS) caused the tissue damage, and cell death of which the main chemical contributed to the production of ROS was XO which eventually generated superoxide anions in the conversion of hypoxanthine to xanthine. A cohort study by Petta et al. [38] on patients with histological diagnosis of non-alcoholic fatty liver disease revealed an independent association between hyperuricemia and the severity of liver damage. This current study using histological method further confirmed that hyperuricemia caused damage to the liver. Allopurinol seems to greatly reduce the histological changes in a hyperuricemic group as it plays a role as XO inhibitor by blocking the activity of XO and inhibiting the production of ROS which can reduce the liver damage [37]. Moreover, the ability of allopurinol in reducing liver damage is due to its antioxidant, anti-inflammatory, and antifibrotic properties [39]. The main finding in this histological observation was that onion juice was able to attenuate the histological changes in liver, although the effect was not as effective as allopurinol (Fig. 5). This result was in agreement with Gorinstein et al. [40] on the effect of raw vegetable-supplemented diet on liver changes in rats fed cholesterol as diet supplemented with $500 \mathrm{mg} / \mathrm{kg}$ of raw onion showed to have a protective effect toward liver damage. Quercetin was believed to be the responsible component in eliminating the ROS and increasing of antioxidant activity in the organism. This was the possible mechanism led to the improvement in liver damage when the hyperuricemic rats were treated with onion juice. Apines-Amar et al. [41] revealed that dietary supplementation of onion was able to reduce stress and imparted protective effects on kidney and liver tissues in brown-marbled grouper. In the kidney, hyperuricemia may induce renal vascular damage. A condition of mild hyperuricemia is related to the diminish in renal blood flow and increase the renal vascular resistance, regardless the level of arterial pressure, and glomerular filtration rate. This is believed to be the underlying mechanism between hyperuricemia and renal damage [42]. Interestingly, the effect of onion juice on kidney histological profile of hyperuricemic group was not significant as compared to hyperuricemic control group as in Fig. 6. This finding was not in agreement with other previous studies. A study by Suru [43] postulated the ability of onion to restore the renal damage induced by cadmium in a significant dosedependent manner. The significant decreased in lipid peroxidation and glutathione-S transferase activity and increased of renal glutathione, superoxide dismutase, catalase, and $\mathrm{Na}+/ \mathrm{K}+-$ ATPase activity in rats after received onion further confirmed the protective effect of onion. Another study revealed the antioxidant-rich fresh onion juice was able to decrease cell injury such as apoptosis in tubular and nephrons in rats infected by Toxoplasma gondii [44]. Moreover, Kensara [22] suggested the antioxidant action of high content of Vitamin $\mathrm{C}$ in onion in protecting renal damage. However, this protective effect of renal damage was not observed in this study. This might be due to different species of onion used and different doses of onion juice received by the animal. The findings of this study regarding the protective effects against liver and

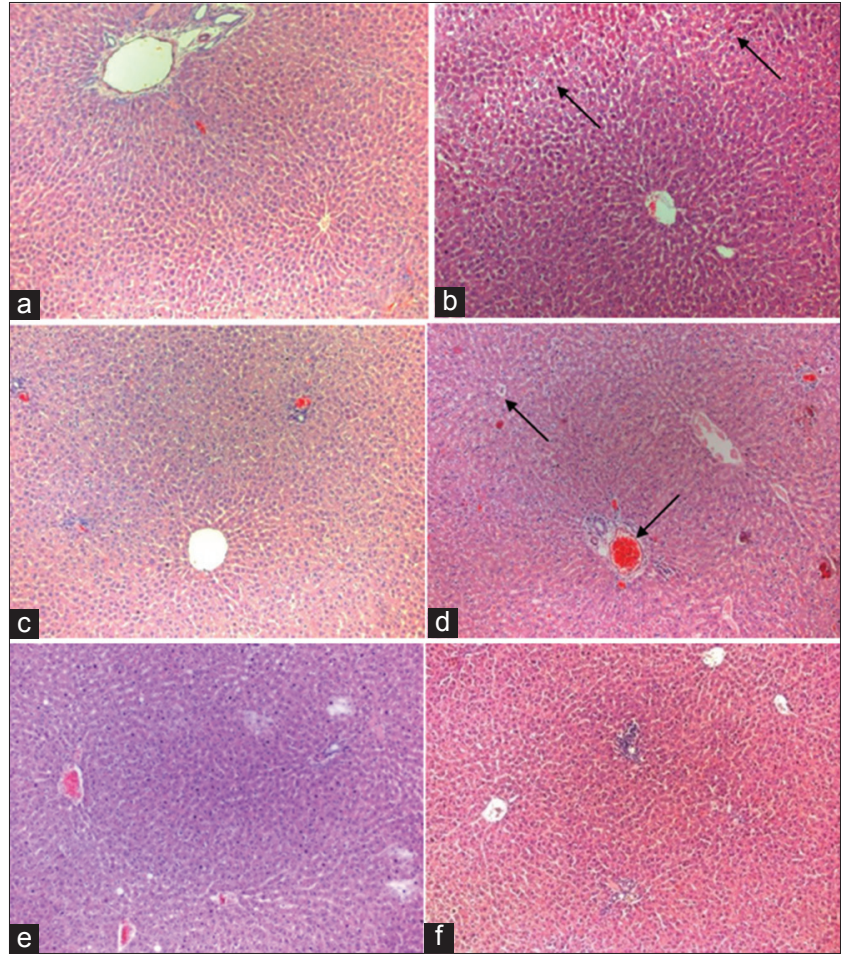

Fig. 5: Histological changes in liver of representative rats of each group ( $\mathrm{H}$ and $\mathrm{E}, \times \mathbf{1 0 0}$ ). (a) Normal control group: Showing normal liver morphology; (b) hyperuricemic control group: Showing apoptosis, some ballooning of hepatocytes, and congestion of blood vessels; (c) hyperuricemic $+5 \mathrm{mg} / \mathrm{kg}$ / day allopurinol: Histological changes had greatly reduced; (d) hyperuricemic $+3.5 \mathrm{~g} / \mathrm{kg} /$ day onion juice: $>50 \%$ ballooning of hepatocyte and congestion of blood vessels were clearly seen; (e) hyperuricemic $+7.0 \mathrm{~g} / \mathrm{kg} / \mathrm{day}$ onion juice: Showing a slight reduction in ballooning of hepatocyte and congestion of blood vessels; (f) hyperuricemic $+10.5 \mathrm{~g} / \mathrm{kg} / \mathrm{day}$ onion juice: Ballooning of hepatocytes and congestion of blood vessels were greatly reduced

kidney were not conclusive as no oxidative stress markers had been studied.

\section{CONCLUSION}

Onions were able to reduce serum uric acid level in induced hyperuricemic rats in a dose-dependent manner where the highest dose of onion appeared to have the inhibitory effect almost similar to allopurinol, the most common pharmacological drug used to reduce uric acid level. At the same time, onions increased the total antioxidant status of hyperuricemic rats. Although the value was not significant enough to prove the antioxidant ability of onion in this study, there were other previous studies reported this characteristic of onion. Interestingly, onions were able to restore the liver damage caused by hyperuricemia but not in kidney and the underlying mechanism led to this result were still unclear. Thus, the protective effect of onion toward liver and kidney was inconclusive as there was no other oxidative stress marker to measure the lipid peroxidation and it remained speculative whether the antioxidant action of onion may have a protective effect against liver and kidney damage induced by hyperuricemia.

\section{ACKNOWLEDGMENT}

The authors would like to thank Faculty of Medicine and Health Sciences, Universiti Putra Malaysia (UPM) for providing infrastructural facilities to carry out this study as well as Universiti Tun Hussein Onn Malaysia (UTHM), Vot E15501 for funding publication fee of this manuscript. 


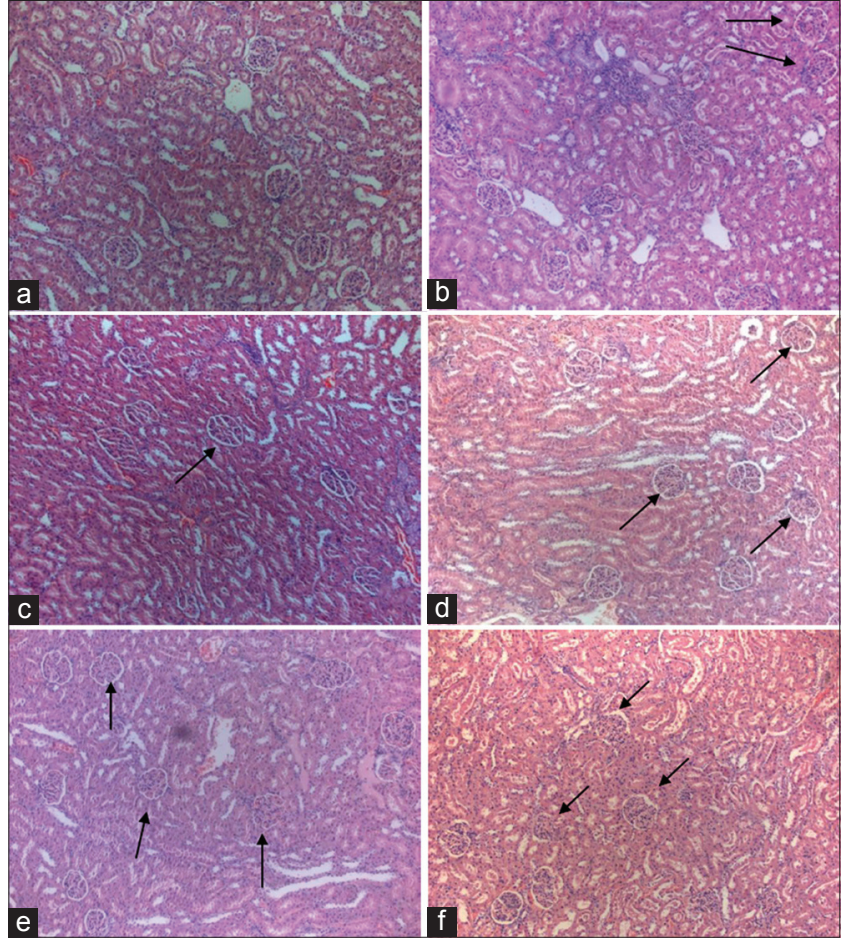

Fig. 6: Histological changes in kidney of representative rats of each group ( $H$ and $E, \times 100)$. (a) Normal control group: Showing normal structure of capsule; (b) hyperuricemic control group: $>\mathbf{5 0 \%}$ decrease in the Bowman's space with congestion of blood vessels; (c) hyperuricemic $+5 \mathrm{mg} / \mathrm{kg} /$ day allopurinol: Showing normal structure of Bowman's space, but still, there were congestions of blood vessels; (d) hyperuricemic+

$3.5 \mathrm{~g} / \mathrm{kg} /$ day onion juice: About $50 \%$ of the Bowman's capsule decrease in its Bowman's space with congestion of blood vessels; (e) hyperuricemic $+7.0 \mathrm{~g} / \mathrm{kg} / \mathrm{day}$ onion juice: The histological changes were almost similar to hyperuricemic control group; (f) hyperuricemic $+10.5 \mathrm{~g} / \mathrm{kg} /$ day onion juice: The histological changes were almost similar to hyperuricemic control group

\section{AUTHORS CONTRIBUTION}

The work was suggested and designed by Asmah Rahmat. Choo Yen Leng performed the experimental work and assessed the data. The review manuscript was drafted by Asmah Rahmat and Fazleen Izzany Abu Bakar. The manuscript was edited by Mohd Fadzelly Abu Bakar. Authors read and approved the final manuscript.

\section{CONFLICTS OF INTERESTS}

Authors declare no conflict of interest

\section{REFERENCES}

1. Chernecky CC, Murphy-Ende K. Acute Care Oncology Nursing. $2^{\text {nd }}$ ed. St. Louis, Mo: Saunders/Elsevier; 2009.

2. Perez-Ruiz F. Treating to target: A strategy to cure gout. Rheumatology (Oxford) 2009;48 Suppl 2:ii9-14

3. Hollis-Moffatt JE, Gow PJ, Harrison AA, Highton J, Jones PB, Stamp LK, et al. The SLC2A9 nonsynonymous arg265His variant and gout: Evidence for a population-specific effect on severity. Arthritis Res Ther 2011:13:R85

4. Mohd A, Gupta Ed, Loh Y, Gandhi C, D'Souza B, Gun S, et al. Clinical characteristics of gout: A hospital case series. Malays Fam Physician 2011:6:72-3.

5. Hak AE, Curhan GC, Grodstein F, Choi HK. Menopause, postmenopausal hormone use and risk of incident gout. Ann Rheum Dis 2010;69:1305-9.

6. Sachs L, Batra KL, Zimmermann B. Medical implications of hyperuricemia. Med Health R I 2009;92:353-5.

7. Kutzing MK, Firestein BL. Altered uric acid levels and disease states.
J Pharmacol Exp Ther 2008;324:1-7.

8. Packia Lekshmi NC, Viveka S, Viswanathan MB, Shobi TM, Jeeva S, Brindha JR. High performance thin layer chromatography profile of quarcetin in three cultivars of Allium cepa and its antimicrobial activity against bacterial cultures. Asian J Pharm Clin Res 2015;8:213-8.

9. Mahfouz MA, Maher AE, Mortada ME, Eman AE, Ezzat EA. Chromatographic isolation of Allium cepa (ssp. Red onion) and its cytotoxic activity against human liver carcinoma cell lines (HEPG2). Int J Pharm Pharm Sci 2014;6:108-11.

10. Willis L. Basic Steps to Godly Fitness: Strengthening Your Body and Soul in Christ. United States of America: Harvest House Publishers; 2005.

11. Nuutila AM, Puupponen-Pimiä R, Aarni M, Oksman-Caldentey KM. Comparison of antioxidant activities of onion and garlic extracts by inhibition of lipid peroxidation and radical scavenging activity. Food Chem 2003;81:485-93.

12. Shon MY, Choi SD, Kahng GG, Nam SH, Sung NJ. Antimutagenic, antioxidant and free radical scavenging activity of ethyl acetate extracts from white, yellow and red onions. Food Chem Toxicol 2004;42:65966.

13. Haidari F, Rashidi MR, Keshavarz SA, Mahboob SA, Eshraghian MR, Shahi MM, et al. Effects of onion on serum uric acid levels and hepatic xanthine dehydrogenase/xanthine oxidase activities in hyperuricemic rats. Pak J Biol Sci 2008;11:1779-84.

14. Hall IH, Scoville JP, Reynolds DJ, Simlot R, Duncan P. Substituted cyclic imides as potential anti-gout agents. Life Sci 1990;46:1923-7.

15. Ding XQ, Pan Y, Wang X, Ma YX, Kong LD. Wuling san ameliorates urate under-excretion and renal dysfunction in hyperuricemic mice. Chin J Nat Med 2013;11:214-21.

16. Dollah MA, Parhizkar S, Latiff LA, Bin Hassan MH. Toxicity effect of nigella sativa on the liver function of rats. Adv Pharm Bull 2013;3:97102.

17. Batts KP, Ludwig J. Chronic hepatitis. An update on terminology and reporting. Am J Surg Pathol 1995;19:1409-17.

18. Alan S, Lowe JS, Young B. Wheater's Basic Histopathology: A Color Atlas and Text. Edinburgh: Churchill Livingstone Elsevier; 2002.

19. Scherrer R. Anti-Inflammatory Agents Part II: Chemistry and Pharmacology. United States of America: Elsevier; 2012.

20. Haidari F, Rashidi MR, Mohammad-Shahi M. Effects of orange juice and hesperetin on serum paraoxonase activity and lipid profile in hyperuricemic rats. Bioimpacts 2012;2:39-45.

21. Schwartz IF, Grupper A, Chernichovski T, Grupper A, Hillel O, Engel A, et al. Hyperuricemia attenuates aortic nitric oxide generation, through inhibition of arginine transport, in rats. J Vasc Res 2011;48:252-60.

22. Kensara OA. Protective effect of vitamin $\mathrm{C}$ supplementation on oxonate-induced hyperuricemia and renal injury in rats. Int $\mathrm{J}$ Nutr Metab 2013;5:61-8.

23. Khanna D, Fitzgerald JD, Khanna PP, Bae S, Singh MK, Neogi T, et al. 2012 American college of rheumatology guidelines for management of gout. Part 1: Systematic nonpharmacologic and pharmacologic therapeutic approaches to hyperuricemia. Arthritis Care Res (Hoboken) 2012;64:1431-46.

24. Hu QH, Jiao RQ, Wang X, Lv YZ, Kong LD. Simiao pill ameliorates urate underexcretion and renal dysfunction in hyperuricemic mice. J Ethnopharmacol 2010;128:685-92.

25. Haidari F, Keshavarz SA, Mohammad Shahi M, Mahboob SA, Rashidi MR. Effects of parsley (Petroselinum crispum) and its flavonol constituents, kaempferol and quercetin, on serum uric acid levels, biomarkers of oxidative stress and liver xanthine oxidoreductase aactivity in Oxonate-induced hyperuricemic rats. Iran J Pharm Res 2011;10:811-9.

26. Rodrigues AS, Pérez-Gregorio MR, García-Falcón MS, Simal-Gándara J, Almeida DP. Effect of meteorological conditions on antioxidant flavonoids in portuguese cultivars of white and red onions. Food Chem 2011;124:303-8.

27. Hu QH, Zhang X, Wang X, Jiao RQ, Kong LD. Quercetin regulates organic ion transporter and uromodulin expression and improves renal function in hyperuricemic mice. Eur J Nutr 2012;51:593-606.

28. Choi HK, Gao X, Curhan G. Vitamin C intake and the risk of gout in men: A prospective study. Arch Intern Med 2009;169:502-7

29. Purwantiningsih HA, Purwantini I. Anti-hyperuricemic activity of the kepel (Stelechocarpus burahol (Bl.) Hook. F. \& Th.) leaves extract and xanthine oxidase inhibitory study. Int J Pharm Pharm Sci 2010;2:122-7.

30. George J, Carr E, Davies J, Belch JJ, Struthers A. High-dose allopurinol improves endothelial function by profoundly reducing vascular oxidative stress and not by lowering uric acid. Circulation 2006; $114: 2508-16$ 
31. Feig DI, Soletsky B, Johnson RJ. Effect of allopurinol on blood pressure of adolescents with newly diagnosed essential hypertension: A randomized trial. JAMA 2008;300:924-32.

32. Lee HY, Ariyasinghe JT, Thirumoorthy T. Allopurinol hypersensitivity syndrome: A preventable severe cutaneous adverse reaction? Singapore Med J 2008;49:384-7.

33. Halevy S, Ghislain PD, Mockenhaupt M, Fagot JP, Bavinck JN, Sidoroff A, et al. Allopurinol is the most common cause of StevensJohnson syndrome and toxic epidermal necrolysis in Europe and Israel. J Am Acad Dermatol 2008;58:25-32.

34. Naghavi M, John R, Naguib S, Siadaty MS, Grasu R, Kurian KC, et al. $\mathrm{PH}$ heterogeneity of human and rabbit atherosclerotic plaques; a new insight into detection of vulnerable plaque. Atherosclerosis 2002; 164:27-35.

35. Stratil P, Klejdus B, Kubáň V. Determination of total content of phenolic compounds and their antioxidant activity in vegetables evaluation of spectrophotometric methods. J Agric Food Chem 2006;54:607-16.

36. Gorinstein S, Park YS, Heo BG, Namiesnik J, Leontowicz H, Leontowicz M, et al. A comparative study of phenolic compounds and antioxidant and antiproliferative activities in frequently consumed raw vegetables. Eur Food Res Technol 2009;228:903-11.

37. Liu PG, He SQ, Zhang YH, Wu J. Protective effects of apocynin and allopurinol on ischemia/reperfusion-induced liver injury in mice. World J Gastroenterol 2008;14:2832-7.
38. Petta S, Cammà C, Cabibi D, Di Marco V, Craxì A. Hyperuricemia is associated with histological liver damage in patients with non-alcoholic fatty liver disease. Aliment Pharmacol Ther 2011;34:757-66.

39. Aldaba-Muruato LR, Moreno MG, Shibayama M, Tsutsumi V, Muriel P. Protective effects of allopurinol against acute liver damage and cirrhosis induced by carbon tetrachloride: Modulation of NF- $\mathrm{BB}$, cytokine production and oxidative stress. Biochim Biophys Acta 2012;1820:65-75.

40. Gorinstein S, Leontowicz H, Leontowicz M, Najman K, Bielecki $\mathrm{W}$, Ham KS, et al. Aorta and liver changes in rats fed cholesterolcontaining and raw vegetable-supplemented diets: Experiments in vitro and in vivo. J Agric Food Chem 2011;59:7441-51.

41. Apines-Amar MJ, Amar EC, Faisan JP Jr. Growth, plasma cortisol, liver and kidney histology, and resistance to vibriosis in brown-marbled grouper, Epinephelus fuscoguttatus fed onion and ginger. AACL Bioflux 2013;6:530-8

42. Sánchez-Lozada LG, Tapia E, Santamaría J, Avila-Casado C, Soto V, Nepomuceno T, et al. Mild hyperuricemia induces vasoconstriction and maintains glomerular hypertension in normal and remnant kidney rats. Kidney Int 2005;67:237-47.

43. Suru SM. Onion and garlic extracts lessen cadmium-induced nephrotoxicity in rats. Biometals 2008;21:623-33

44. Gharadaghi Y, Shojaee S, Khaki A, Hatef A, Ahmadi Ashtiani HR, Rastegar $\mathrm{H}$, et al. Modulating effect of allium cepa on kidney apoptosis caused by toxoplasma Gondii. Adv Pharm Bull 2012;2:1-6. 